\title{
COGNITIVE STYLES OF ELITE FOOTBALL REFEREES IN BULGARIA
}

\section{Ivan Ivanov, Georgi Ignatov}

\begin{abstract}
In the game of football the referee is one of the most important figures. His role is an integral part of the game. The modern game has very fast and complicated situations and the referee has to be equipped with professional skills and responsible for enforcing the laws of the game. Every second there is a lot of information on the pitch which has to be integrated. Psychologists are trying to describe this processes and to separate the different styles of information receiving and decision making. Kirton Adaption/Innovation Inventory, KAI (Kirton, 1976), adapted by S. Vasileva, 2003. The questionnaire contains 33 items: hree scales - originality, efficacy, conformity. The cognitive styles are part of the complete adaptation to the game and the preferred way of thinking in most of the game situations. The basic direction of this report is to carry out theoretical and empirical research on the cognitive styles of elite referees in Bulgaria. The main part of the report is a comparison between referees in first league, second league, U17 and U19 league. Typically the number of the referees in that study is 116. We suggest that the three styles (conformity, originality, efficiency) in this study could be different according to the experience, age and gender characteristics of the referees.
\end{abstract}

Key words: cognitive styles, football referees, football, information processes

\section{Introduction}

The football refereeing is an area with strategic meaning, on one side in the policy of the European and World Football Federations, and on the other in all national football association. It is a center and important part of the game. The refereeing is exclusively current problem in its theoretical and practical aspects. In the modern football the referee is the only individual who has full rights to enforce the rules of the game. He has direct responsibility to conduct every match according to the requirements and spirit of the game rules. In this multidimensional activity the referees must behave like good leaders, competent, objective and fair judges, with knowledge about the game of football, and to practice in a creative way the game rules and the principles of the sport morale. Meanwhile they are working with people and have to be equipped with well developed psychological and pedagogical skills.

The term cognitive style is a psychological category which represents consistency in the way that people use and analyze information (Ausburn \& Asburn, 1978). Messick (1976) defines the cognitive style as stable attitudes and preferences or learned strategies, which determine the individual way of perception, memorising, thinking and problem solving. Witkin et. al., (1977) describe the cognitive style as individual differences in the way that people perceive, think, solve problems and learn. There are many interpretations and theories, but most of the authors often use descriptions which define the cognitive styles as a preferred way of perception and information use, as well as problem solving in different complicated situations.

There is a lot of research on cognitive styles in football, but most of it is with players. Thelwell (2005) carried out a study to evaluate the psychological strength in players from English Premiere League. The cognitive ability of the players to recognize the situation is one of the most important factors which determine the performance. The highlight of Witkin's theory - (dependence - independence of the field) is based on a lot of research with different athletes (Kane, 1972; Drouin et. al., 1986; Cano \& Marquez, 1995). A large number of the researchers find that participants with field dependence style have the advantage in collective sports. On the other side the competitors with field independence have more success in individual sports. Later, there were surveys which confirmed the hypothesis that there is no difference in cognitive styles in the different sports (Drouin et. al., 1986; Brady, 1995). Suda (1999) researched cognitive styles of football players and tried to find correlation with their sport performance. His data show that from the perspective of the theory for dependence - independence 
of the field, the elite players have a clearer tendency to have a dependence field style. T. Yancheva \& I. Ivanov (2014) in their research with football players show that the styles of attention which are associated with a positive game effect have higher results.

Football refereeing is highly related to the football game. According to Yancheva and Ignatov (2007) the elite football referees have higher security urges. They have anxiety, intensive emotional reactions and need support from others in situations of stress and risk. In another survey of the same authors (Yancheva and Ignatov, 2012), they compiled a psychological profile of football referees and bring up important ideas for the referees' preparation. There is a difference between elite and non-elite referees. Some of them have an internal locus of control and others have an external one (Ignatov, 2007).

The following research is based on all this factors, questions and problems about the psychological aspects of Bulgarian football referees. We try to find out the importance of styles and their role in game situations.

The aim of the research is to explore the cognitive styles of elite referees in Bulgaria.

To achieve that aim we set following tasks:

1. To find out and measure cognitive styles of football referees;

2. To find out how the factors such as gender, age, professional experience and qualification level influenced the cognitive styles.

3. To find, explore and compare the styles between referees and assistant-referees.

\section{Methods}

The following research was realized during the winter seminar of professional football referees in Sliven, Bulgaria - February 2017. Firstly with referees and assistants from FPFL (First Professional Football League) - 6-8 February; referees and assistants from SPFL (Second Professional Football League) - 11-13 February; referees and assistants from Elite youth groups - 13-14 February. Every referee completed a test (questionnaire) - Kirton Adaption/Innovation Inventory - KAI (Kirton, 1976), adapted from S. Vasileva, 2003. The questionnaire contains 33 items spread out in tree scales - Originality, Conformity and Efficiency.
Ivan Ivanov (2017) summarizes that:

$>$ Originality is related to a tendency to move away from the consensus by breaking the ordinary styles of thinking with new ideas;

> Efficiency means consistency, workability, precision and good performance;

$>$ Conformity is the tendency of people to seek in the group authority, rules, security and norms.

The topic of research are cognitive styles - conformity, originality and efficiency of elite football referees in Bulgaria.

The object of the research is the influence of gender, age, professional experience, qualification level and international experience on the cognitive styles of referees.

The subjects of the research are 116 football referees: 12 referees of FPFL ( 5 of them - international); 22 assistants from FPFL (7 of them international), 14 referees and 24 assistants from SPFL; 20 referees and 16 assistants from Elite youth groups, 2 women referees ( 1 international) and 6 women assistants (2 of them international).

The data from the research are processed with statistical software SPSS19 and variance and comparative analysis. The distribution of the data was deter-

mined by the test of Kolmogorov - Smirnov.

\section{Results and discussion}

The results of the average values show that originality $(M=2,70)$ is the style with the highest score - Figure.1. This style is typical for persons who like and try to be creative, to accumulate new experience and to progress with little information about the tasks.

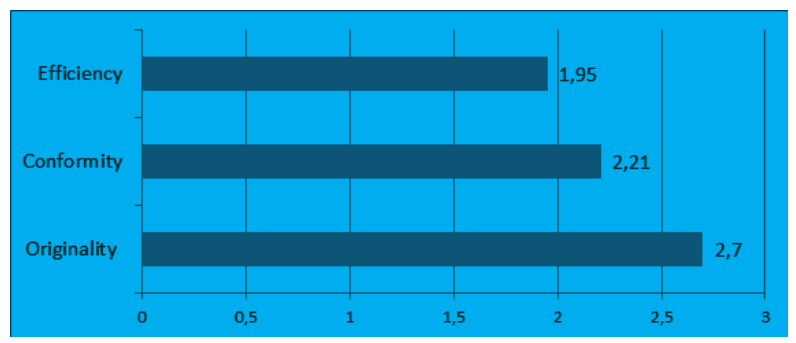

Figure 1. Average values for the cognitive styles of surveyed referees

The comparative analysis of the data by gender does not show any statistically significant differences be- 
tween these three cognitive styles. In this research we can't be sure about the results, because the female referees are only eight, and men and women are not equally represented. The data from this survey can be analyzed for futures hypothesis and ideas.

The comparative analysis of data by position shows that referees have higher level of the cognitive style Originality than their assistants - Table 1 . They have much more responsibilities. They need to react very quickly and correctly in frequently changing situations. The originality style helps them to perform well, during the game, there are no two same moments on the pitch.

In this research there is no statistically significant differences in the other two cognitive styles - conformity and efficiency.

Table 1. Results from the comparative analysis of data by position of the pitch

\begin{tabular}{|c|c|c|c|c|c|c|}
\hline Cognitive styles & position & $N$ & $M$ & $S D$ & $t$ & $\alpha$ \\
\hline \multirow{3}{*}{ Originality } & Referees & 48 & 2.89 & .39 & \multirow{3}{*}{2,66} & \multirow{3}{*}{0,03} \\
\hline & Assistants & 68 & 2.60 & .47 & & \\
\hline & Total & 116 & & & & \\
\hline \multirow{3}{*}{ Conformity } & Referees & 48 & 2.22 & .26 & \multirow{3}{*}{$-1,22$} & \multirow{3}{*}{0,22} \\
\hline & Assistants & 68 & 2.08 & .63 & & \\
\hline & Total & 116 & & & & \\
\hline \multirow[t]{3}{*}{ Efficiency } & Referees & 48 & 1.95 & .39 & \multicolumn{2}{|c|}{$-1,220,22$} \\
\hline & Assistants & 68 & 1.98 & .47 & & \\
\hline & Total & 116 & & & & \\
\hline
\end{tabular}

The next variable which we take is age (Table 2). For the goals of the research we separate the people in three groups - from 20 to 26 , from 27 to 33 and from 34 to 42 .

Table 2. Results from the comparative analysis of data by age category

\begin{tabular}{|c|c|c|c|c|c|c|}
\hline \multicolumn{2}{|c|}{ Cognitive styles } & $\mathbf{N}$ & Mean & SD & $F$ & $\alpha$ \\
\hline \multirow{4}{*}{ Originality } & $20-26$ & 18 & 2.53 & .41 & \multirow{4}{*}{2,31} & \multirow{4}{*}{0,01} \\
\hline & $27-33$ & 64 & 2.68 & .28 & & \\
\hline & $34-42$ & 34 & 2.79 & .34 & & \\
\hline & Total & 116 & 2.69 & .32 & & \\
\hline \multirow{4}{*}{ Conformity } & $20-26$ & 18 & 2.25 & .40 & \multirow{4}{*}{2,00} & \multirow{4}{*}{0,04} \\
\hline & $27-33$ & 64 & 2.14 & .37 & & \\
\hline & $34-42$ & 34 & 2.03 & .43 & & \\
\hline & Total & 116 & 2.21 & .39 & & \\
\hline \multirow{4}{*}{ Efficiency } & $20-26$ & 18 & 1.90 & .70 & \multirow{4}{*}{4,23} & \multirow{4}{*}{0,15} \\
\hline & $27-33$ & 64 & 1.98 & .61 & & \\
\hline & $34-42$ & 34 & 1.92 & .60 & & \\
\hline & Total & 116 & 1.95 & .62 & & \\
\hline
\end{tabular}

The styles are a characteristic which can be developed through individual experience and the specifics of activity and profession. The results show that originality increases with the age of the referees. One of the reasons here is social and life experience. In other words, the football referee profession requires specific skills. Every one individual has to observe and react to quick situations and to make decisions in less than a second. Sometimes he or she has to be flexible and react differently in different game episodes, and in this case the professional experience is very important. The conclusion is - the best referees have a higher level of original thinking and very well developed skills for movement on the pitch. There are statistically significant differences between age categories $-\mathrm{F}=2,31, \alpha=0,01$ (Table 2).

The next scale is conformity, the feature of people who are with high agreement with the group and very rarely resist other opinions. The results in our research show that this characteristic exists in lower levels in older referees. The young professionals are still uncertain about their skills and need more help and support and still don't have enough authority. There is a significant difference between younger and older referees $-F=2,00, \alpha=0,04$. The age is a predictor for conformity level - older age means lower conformity and agreement. In many cases the older professionals have higher qualifications and that's related to the individualism. 
The referee is the most important person during the course of a match, he (she) has to have leading skills and autonomy.

The scale efficiency has the highest level in the 27-33 age range, but the differences are not statistically significant.

Professional experience is the next independent variable in our research (Table 3 ).

Table 3. Results from the comparative analysis of data by professional experience

\begin{tabular}{|c|c|c|c|c|c|c|}
\hline \multicolumn{2}{|c|}{ Cognitive styles } & $\mathbf{N}$ & Mean & SD & $\mathbf{F}$ & $\alpha$ \\
\hline \multirow{4}{*}{ Originality } & $3-9$ & 44 & 2.58 & .32 & \multirow{4}{*}{3,00} & \multirow{4}{*}{0,04} \\
\hline & $\begin{array}{l}10- \\
17\end{array}$ & 58 & 2.61 & .32 & & \\
\hline & $18-25$ & 14 & 2.75 & .33 & & \\
\hline & Total & 116 & 2.69 & .32 & & \\
\hline \multirow{4}{*}{ Conformity } & $3-9$ & 44 & 2.29 & .33 & \multirow{4}{*}{4,23} & \multirow{4}{*}{0,01} \\
\hline & $\begin{array}{l}10- \\
17\end{array}$ & 58 & 2.21 & .41 & & \\
\hline & $18-25$ & 14 & 2.15 & .49 & & \\
\hline & Total & 116 & 2.21 & .39 & & \\
\hline \multirow{4}{*}{ Efficiency } & $3-9$ & 44 & 1.95 & .58 & \multirow{4}{*}{0,23} & \multirow{4}{*}{0,771} \\
\hline & $\begin{array}{l}10- \\
17\end{array}$ & 58 & 1.96 & .65 & & \\
\hline & \begin{tabular}{|l}
$18-$ \\
25 \\
\end{tabular} & 14 & 1.92 & .66 & & \\
\hline & Total & 116 & 1.95 & .62 & & \\
\hline
\end{tabular}

The results show statistically significant differences for two scales (Table 3). First, originality increases with the years in the profession $(\mathrm{F}=3,00$, $\alpha=0,04)$. In this table we have higher levels of originality with increasing experience. The practice is important for creative decisions, progressing with little information and quick information processing. The success of the referee depends on his original thinking, there is a close relationship between psychological skills and experience.

The scale conformity is lower in the more experienced professionals $-\mathrm{F}=4,23, \alpha=0,01$. The agreement with the group is not so important when you follow the rules and judge in right way. The referees with only one or two years' experience are still uncertain, with high anxiety and expectations for mistakes and the consensus with others gives them more peace of mind.
The efficiency scale has the highest level in the period of 10 to 17 years in the profession, but we can't draw conclusions, because there is no statistically significant difference between different categories of experience.

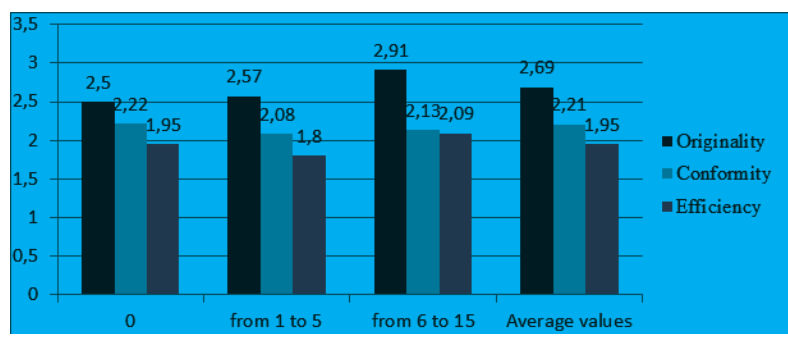

Figure 2. Average values of cognitive styles by international experience

To become an international referee is the goal of every one who chooses this profession. In our survey we tries to find the most valuable cognitive styles. And after we have described these qualities, the referees can use this information to develop their psychological skills. The results point out that the originality style has the highest level in participants with the greatest international experience from 6 to 15 years (Figure 2). There are significant differences $-\mathrm{F}=3,00, \alpha=0,04$.

\section{Conclusions:}

$>$ The obtained results support the hypothesis that the originality cognitive style is leading in elite referees in Bulgaria;

$>$ The oldest and the most experienced referees have the highest level of originality, creativity, quick decision making and use of information;

$>$ The style conformity goes down with the increase of age and experience;

$>$ The elite professionals with high level of international experience prefer individual mental and behavioral strategies and decisions (originality cognitive style);

$>$ In our research we did not find statistically significant differences of cognitive style efficiency by gender, age category or professional experience;

$>$ The obtained results can be an important direction for football referees, their mentors and sport psychologists for better understanding and development;

$>$ This article is a basic level for future studies in field of Bulgarian football refereeing. 


\section{References}

Ausburn, L. J. \& Ausburn, F. B. (1978). Cognitive styles: Some information and impications for instructional design. Educational communication and Technology, 26, 337-354.

Brady, F. (1995). Sports skill classification, gender, and perceptual style. Perceptual and Motor Skills, 81, 611620.

Cano, J. E. \& Marquez, S. (1995). Field dependence-independence of male and female Spanish athletes. Perceptual and Motor Skills, 80, 1155-1161.

Drouin, D., Talbot, S., \& Goulet, C. (1986). Cognitive styles of French Canadian athletes. Perceptual and Motor Skills, 63, 1139-1142.

Ignatov.G (2012). Experimental validation of training method for young football referees. Dissertation. NSA „Vassil Levski“, department „Football and tennis“.

Ivanov, I. (2017). Cognitive styles and game efficiency in football. Dissertation. NSA „Vassil Levski“, department „Psychology, pedagogy, sociology“.

Kane, J. E. (1972). Personality, body concept and performance. In J.E. Kane (Ed.), Psychological aspects of phys ical education and sport (pp. 91-127). London: Western Printing Services.

Kirton, M., J. (1976). Adaptors and innovators, a description and measure. Journal of Applied Psychology, 61, 622-629.

Messick, S. (1976). Personality consistencies in cognition and creativity. In S. Messick (Ed.). Individuality in learning. (pp.4-23). San Francisco: Jossey-Bass.

10. Sadler-Smith, E. \& Badger, B. (1998). Cognitive style, learning and innovation. Technology Analysis and Strategic Management, 10, 247-265.
Suda (1999) The relationship between cognitive style of soccer players, Bulletin of institute of Physical Education, Keio University, 38, 1-9.

Talbot, R. P. (1989). Valuing differences in thinking style to improve individual and team performance. National Productivity Review, 9, 35-50.

Thelwell, R. (2005). Defining and understanding mental toughness in soccer. Journal of Applied Sport Psychology, 17, 326-332

Witkin, H., A., Moore, C. A., Goodenough, D. R., \& Cox, P. W. (1977). Field dependent and field independent cognitive styles and their educational implications. Review of Educational Research, 47, 1-64.

Yancheva, T., Ignatov, G. (2007). Psychology of football refereeing. Medicine and sport, 4, 25-28.

Yancheva, T., Ignatov, G. (2013). Psychological profile of football referee. Fifth international scientific conference. Vol.,Modern tendency of physical education“. University publishing house „St. Kliment Ohridski”. P, 515-523.

Yancheva, T., Ivanov, I. (2014). Bulgarian adaptation of Test of Soccer Attentional Style" (TSAS, A.C. Fisher \& A.H. Taylor (1980), Personality, motivation, sport. Volume 19. NSA-PRES, 314-322.

\section{For correspondence:}

Assistant Ivan Ivanov, $\mathrm{PhD}$

Assoc. Prof. Georgi Ignatov, PhD

National Sports Academy „Vassil Levski“

Sofia University “St. Kliment Ohridski”

Department „Psychology, pedagogy and sociology”

Department of sport

E-mail: ywan13@abv.bg

E-mail: gochev730626@abv.bg 